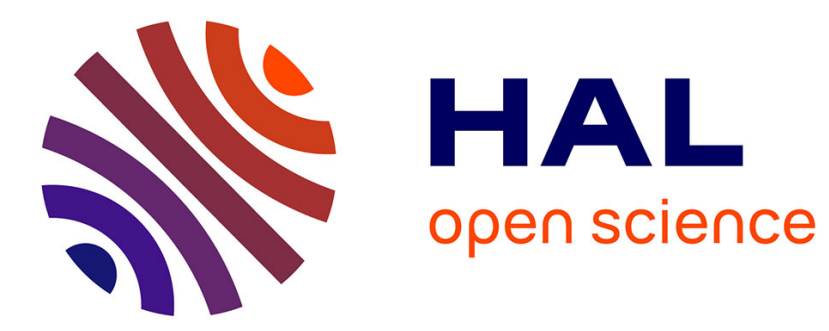

\title{
The Search Coil Magnetometer for THEMIS
}

A. H. Roux, Olivier Le Contel, Christophe Coillot, Abdel Bouabdellah, Bertrand de La Porte, Dominique Alison, Sébastien Ruocco, Marie-Cécile Vassal

\section{- To cite this version:}

A. H. Roux, Olivier Le Contel, Christophe Coillot, Abdel Bouabdellah, Bertrand de La Porte, et al.. The Search Coil Magnetometer for THEMIS. Space Science Reviews, 2008, 141 (1-4), pp.265-275. 10.1007/s11214-008-9455-8 . hal-00610316

\section{HAL Id: hal-00610316 https://hal.science/hal-00610316}

Submitted on 21 Jul 2011

HAL is a multi-disciplinary open access archive for the deposit and dissemination of scientific research documents, whether they are published or not. The documents may come from teaching and research institutions in France or abroad, or from public or private research centers.
L'archive ouverte pluridisciplinaire HAL, est destinée au dépôt et à la diffusion de documents scientifiques de niveau recherche, publiés ou non, émanant des établissements d'enseignement et de recherche français ou étrangers, des laboratoires publics ou privés. 


\title{
The Search Coil Magnetometer for THEMIS
}

\author{
A. Roux - O. Le Contel · C. Coillot . \\ A. Bouabdellah · B. de la Porte · D. Alison . \\ S. Ruocco - M. C. Vassal
}

Received: date / Accepted: date

\begin{abstract}
THEMIS instruments incorporate a tri-axial Search Coil Magnetometer (SCM) designed to measure the magnetic components of waves associated with substorm breakup and expansion. The three search coil antennas cover the same frequency bandwidth, from $0.1 \mathrm{~Hz}$ to $4 \mathrm{kHz}$, in the ULF/ELF frequency range. They extend, with appropriate Noise Equivalent Magnetic Induction (NEMI) and sufficient overlap, the measurements of the fluxgate magnetometers. The NEMI of the searchcoil antennas and associated pre-amplifiers is smaller than $0.76 \mathrm{pT} / \sqrt{\mathrm{Hz}}$ at $10 \mathrm{~Hz}$. The analog signals produced by the searchcoils and associated preamplifiers are digitized and processed inside the IDPU, together with data from the EFI instrument. Searchcoil telemetry includes waveform transmission, FFT processed data, and data from a filter bank. The frequency range covered in waveform depends on the available telemetry. The searchcoils and their three axis structures have been precisely calibrated in a quiet site, and the calibration of the transfer function is checked on board usually once per orbit. The tri-axial searchcoils implemented on the five THEMIS spacecraft are working nominally.
\end{abstract}

Keywords First keyword · Second keyword · More

\section{Introduction}

The primary thrust of the Time History and Macroscale Interaction during Substorms (THEMIS) mission is to establish where and when do substorms start, and to determine the nature of the instability involved in this explosive process. In the magnetospheric plasma where binary collisions are almost absent plasma waves are expected to ensure the collisionless dissipation requested by some of substorm models, and, for guided waves, to allow a remote sensing of the dynamics of active regions. The Electric Field Instrument (EFI) and the Search Coil

A. Roux · O. Le Contel · C. Coillot · A. Bouabdellah · B. de la Porte · D. Alison · S. Ruocco

Centre d'étude des Environnements Terrestre et Planétaires (CETP), 10-12 avenue de l'Europe, F-78140 Vélizy, France

Tel.: 33-1-39254998, Fax: 33-1-39254922

E-mail: alain.roux@cetp.ipsl.fr

M. C. Vassal

3D+, 641 rue Hélène Boucher, F-78532, Buc, France 
Magnetometer (SCM) instruments on THEMIS are tailored to investigating the possible role played by waves at substorm breakup and during the expansion phase. THEMIS SCM has a long heritage; earlier versions of the instrument have been built for GEOS 1 and 2, Ulysses, Galileo, Interball, and more recently for Cluster, and Cassini. A description of the design for Cluster can be found in [3,4]. Each instrument had specific characteristics (frequency range, NEMI and weight), tailored to the constrainsts of the missions listed above. Section 2 starts with a short description of science objectives and of the requirements that they imposed on THEMIS SCM. In section 3 we describe the design of THEMIS SCM antennas and pre-amplifiers. Section 4 provides a description of the tests and calibrations applied to the various models (one qualification and five flight models), and compare the performances of THEMIS SCM's to the specifications. Data from SCM are digitized and processed in the DFB/IDPU; the corresponding modes are described in the IDPU paper. Here we simply give a short description (in table 6) of the the main characteristics of various operation modes.

\section{Measurement requirements}

\subsection{Science objectives}

There are basically two types of models for substorm breakup (see for instance [7] en references therein). For the first type of model, magnetic reconnection (MR) occurs first and triggers substorms. In the second type of model, labelled "Current Disruption" (CD), the breakup is triggered by a reduction in the cross-tail current, associated with the development of an instability. In both cases ULF and ELF waves are believed to play a critical role. In the MR models whistler mode waves are expected to accelerate electrons up to large (super-Alfvénic) velocities [8]. Very thin current sheets can also be destabilized by HF tearings in the whistler mode [2]. In CD models the cross tail current is disrupted by HF cross field instability [6], or undergo LF (ballooning modes) instabilities [11] which are coupled to higher frequency waves: ion cyclotron, lower hybrid drift and/or whistler modes. Thus wave observations provide a critical test to substorm scenarios.THEMIS SCM, and EFI (which measure electric fields in the same frequency range) are designed to identify waves associated with the breakup and to investigate their role in substorm dynamics. Furthermore, when the waves are guided, they can be used to help tracking remotely the active region where breakup starts. SCM is also needed to assess the nature of the waves; are they electrostatic (such as lower hybrid waves), or electromagnetic (such as whistler mode waves)?

\subsection{Requirements}

\subsubsection{Frequency range and NEMI}

The science objectives briefly sketched above, and described in more details in a companion paper by [5], have been used to specify the characteristics of THEMIS SCM. We summarize below the main instrument requirements. Among the various types of wave modes listed above, Whistler mode waves have the highest frequency cut-off: $\mathrm{f}_{c e}$ (the electron gyrofrequency), in the regions of interest. This cut-off has been used to fix the maximum frequency to be covered by the SCM. CD is expected to develop in the near-earth plasma sheet, typically around $8 \mathrm{R}_{E}$ [6]. At $8 \mathrm{R}_{E}, \mathrm{~B} \simeq 50 \mathrm{nT}$ is a typical value for the $\mathrm{DC}$ field, then $\mathrm{f}_{c e} \simeq 1.4$ $\mathrm{kHz}$. At the geostationnary orbit $\left(6.7 \mathrm{R}_{E}\right)$, assuming a dipole field one gets $\mathrm{f}_{c e} \simeq 4 \mathrm{kHz}$ while 
during a substorm growth phase where the average equatorial magnetic field is reduced by the effect of the increasing cross tail current one gets $\mathrm{f}_{c e} \simeq 2.8 \mathrm{kHz}$. At $5 \mathrm{R}_{E}$, the dipole field gives $\mathrm{f}_{c e} \simeq 9 \mathrm{kHz}$, which is about twice the maximum frequency covered by the SCM instrument. Since CD is not expected to occur inside of 5-6 $\mathrm{R}_{E}$, and whistler mode waves are damped and/or unguided above $\mathrm{f}_{c e} / 2$, an upper cutoff of the SCM frequency bandwith at $4 \mathrm{kHz}$ has been imposed. Given that the amplitude of waves measured in the plasma sheet by Cluster is typically of the order of $10-100 \mathrm{pT} / \sqrt{\mathrm{Hz}}$ at $10 \mathrm{~Hz}$, the request on SCM NEMI has been fixed to be better than $1 \mathrm{pT} / \sqrt{\mathrm{Hz}}$ at $10 \mathrm{~Hz}$.

\subsubsection{Other requirements}

Given the constrainsts on spacecraft mass, the allocated mass budget was $800 \mathrm{~g}$ (600 $\mathrm{g}$ for the sensors including mounting hardware and $200 \mathrm{~g}$ for the preamplifiers), while the power allocation was fixed to be smaller than $100 \mathrm{~mW}$, for each set of SCM preamplifiers. In order to determine the polarisation of the waves, the direction of the magnetic axis of the antennas has to be known. This requirement has led to request a knowledge of each magnetic axis to be better than 1 degree. In section 3 we show that these requirements are met by the five tri-axis SCM embarked on THEMIS.

\section{Description of the instrument}

\subsection{Modeling}

\subsubsection{Magnetic amplification}

The instrument is based upon the combination of a high magnetic permeability material and a large number of turns which passively detect voltage induced by the changing external field (an AC-current measurement). The high magnetic permeability core amplifies the external magnetic field $[10,9,1]$. This core is located inside two types of windings. The main winding is the sensing element; it has a very large number of turns; here 51600, while the secondary winding is used to introduce a flux feedback in order to flatten the frequency response. It helps stabilizing the response of the instrument and makes it independent of the temperature variation. Figure 1 shows a picture of a search coil before potting. The magnetic amplifi-

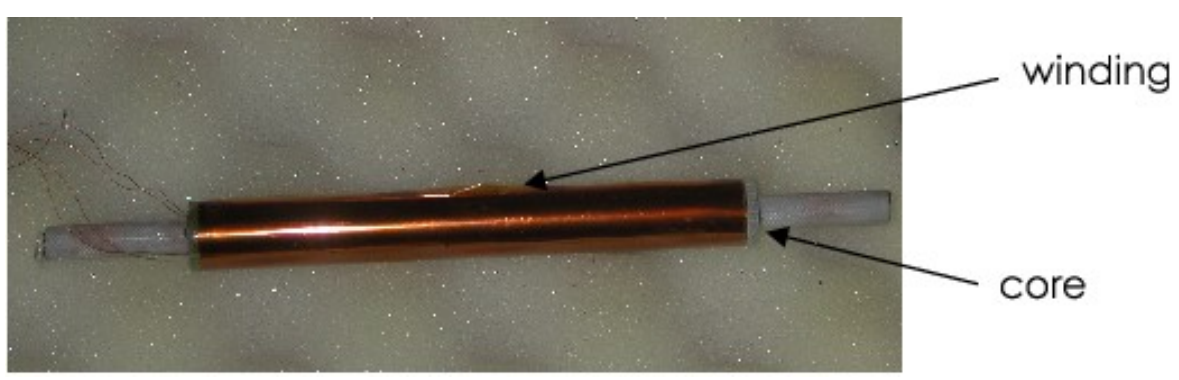

Fig. 1 Picture of a THEMIS search coil before potting

cation, or apparent permeability $\mu_{a p p}$, caracterizes the ratio between the magnetic field at 
a given position in the core $B_{\text {core }}$, and the external magnetic field $B_{\text {ext }}$. One defines a mean apparent permeability that determines the mean field seen inside a winding of length $L$. The main winding has $\mathrm{N}$ turns wound around a core with a relative permeability $\mu_{r}$. In these conditions, the Lenz law $e=-N d / d t(\phi)$ where $\phi$ is the magnetic flux across one loop, gives the modulus of the induced voltage as

$$
e=N S\left(\frac{1}{L} \int_{0}^{L} \mu_{a p p}(l) d l\right) B_{\text {ext }} \omega=N S<\mu_{\text {app }}>B_{\text {ext }} \omega,
$$

$\mathrm{S}$ being the core section, assuming a sinusoidal magnetic perturbation $\left(B_{\text {ext }} \propto \exp (j \omega t)\right)$ and where bracket denotes an averaging along the winding. When a magnetic field is applied to ferromagnetic materials, they magnetize. The intensity of this magnetization depends on the relative permeability of the magnetic material, but also on the shape of the sample via its demagnetizing coefficient $N_{z}$. The latter depends on the ratio $m$ between the length and the diameter of the magnetic core. In the case of a cylinder we utilize the expression:

$$
\mu_{\text {app }}(m)=\frac{B_{\text {core }}}{B_{\text {ext }}}=\frac{\mu_{r}}{\left[1+\left(\mu_{r}-1\right) N z(m)\right]}
$$

For the magnetic material used for THEMIS, the relative permeability is very high, thus $\left(\mu_{r}-1\right) N z(m) \gg 1$ and the previous expression becomes: $\mu_{\text {app }}(m)=1 / N z(m)$. Then, in order to increase the apparent permeability, one must decrease the coefficient of the demagnetizing field, which means to increase the ratio $m$. This can be done either by increasing the length $L$ or decreasing the diameter $d$. In the first case, the size and mass of the sensor is increased, and in the second the intensity of the induced voltage is reduced, since the section of the core is decreased. The design of the THEMIS search coil results from a compromise between these two constrainsts.

\subsubsection{Electrical modeling}

The frequency behaviour can be represented by an RLC circuit excited by a voltage source corresponding to the induced voltage collected by the main winding, as shown in figure 2 . The transmittance (ratio between the output voltage $\mathrm{V}$ and the magnetic field to measure $B$ )

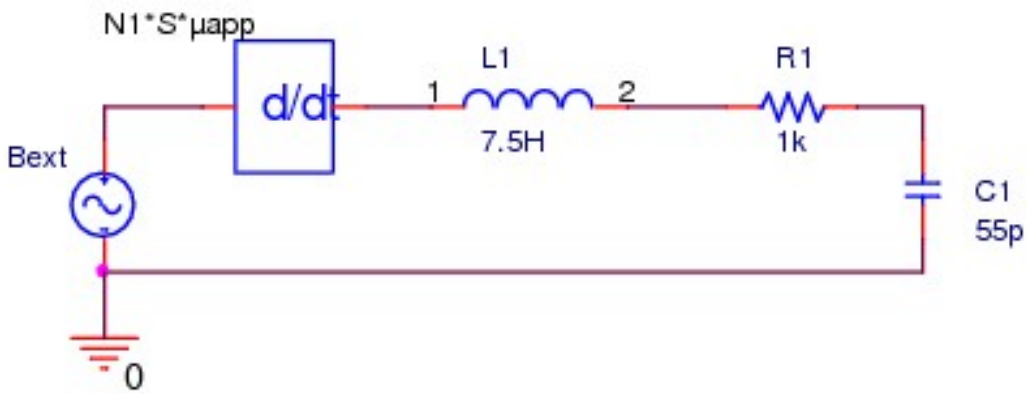

Fig. 2 Electrokinetic representation of a search coil sensor

of such a sensor can be easily put in the following form :

$$
T(j \omega)=\frac{V}{B}=\frac{-j \omega N S \mu_{a p p}}{\left(1-L C \omega^{2}\right)+j R C \omega}
$$




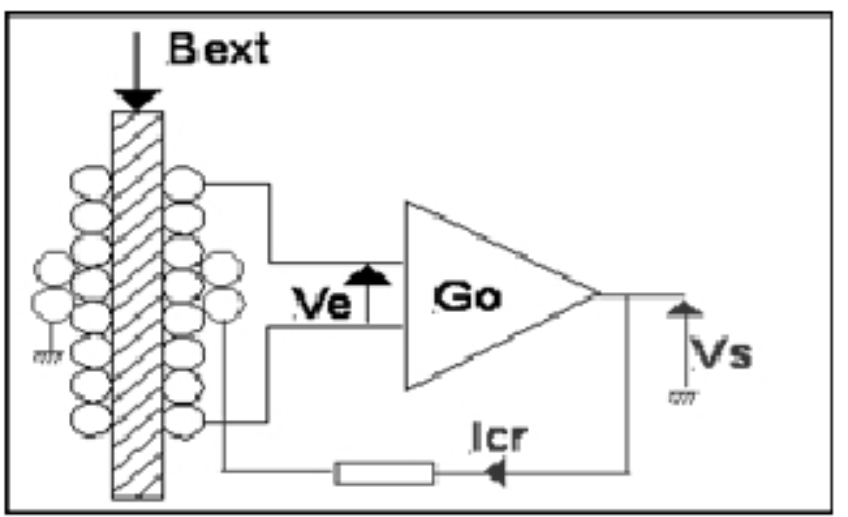

Fig. 3 Principle of fluxmeter with a feedback flux

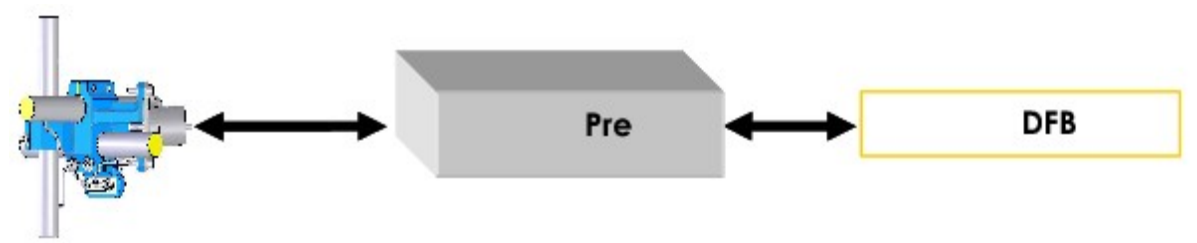

Fig. 4 Block diagram

The sensor has a main resonance which limits its measurement bandwidth and reduces the dynamics. This is because a signal measured at a frequency close to the resonant frequency leads to a high transmittance value. To remove this effect, a feedback is applied on the core field, as shown in figure 3.

\subsection{Design of THEMIS SCM}

\subsubsection{SCM antennas}

The Search Coil Magnetometer consists of three sensors and a pre-amplifier box as shown in figure 4 . The sensors are mounted in a tri-axial configuration to measure the $x, y$, and $\mathrm{z}$ components of the magnetic field in the frequency range of $0.1 \mathrm{~Hz}-4 \mathrm{kHz}$. They are mounted on the tip of a one meter length rigid boom as shown in figure 5 (stowed position). The antenna structure is designed to allow a precise alignment of the sensors with respect to spacecraft axis. Two sensors lie in the spin plane and the third one is parallel to the spin axis. The 3 SCM antennas are held orthogonally on a mechanical structure mounted on a one-probe diameter boom; they are thermally isolated and covered by a thermal blanket of Multi-Layer Insulation (MLI) type. The identical sensor $(18 \mathrm{~cm})$ and its kin $(27 \mathrm{~cm})$ have been previously flown by CETP on more than 7 earth-orbiting and interplanetary missions; most-recently it was flown as part of the Cluster/STAFF experiment. The mass of the SCM antennas and mounting structure is $568 \mathrm{~g}$, compliant with THEMIS specifications (less than 


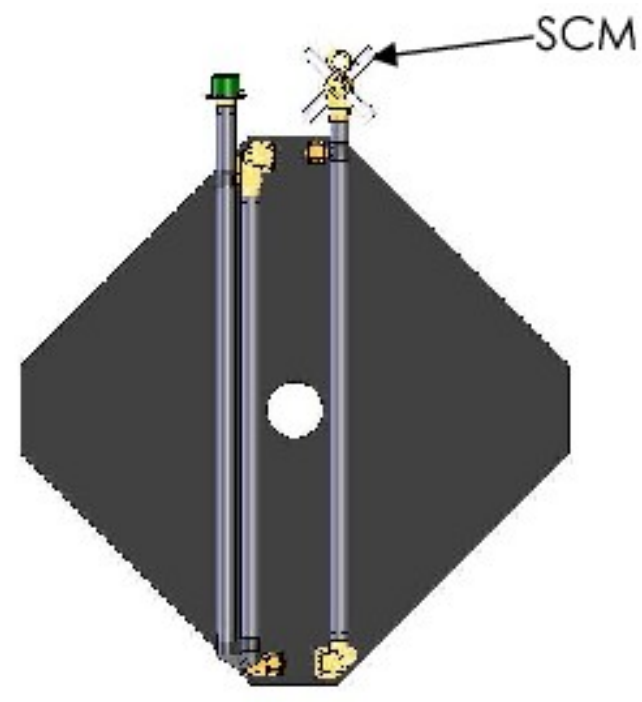

Fig. 5 SCM position on the probe (drawing from UCB)

$600 \mathrm{~g}$ ). An electrostatic shielding is implemented around the search coils to minimise their sensitivity to electric fields.

\subsubsection{Preamplifier design}

Three identical low-power preamplifiers (one for each sensor signal) are mounted in an electrical unit, fixed on the IDPU box. They have been developped using a new technology: multichip module vertical (MCM-V). This technique consists of dividing the circuit in smaller functions. Each function is implemented using bare chips on thin flexible printed circuit boards (PCB), which are piled up to form a compact module (essentially a cube, see figure 6). Layers containing tantalum plates are inserted between the PCBs to protect the sensitive components against radiation. These plates are placed only on top and bottom of these sensitive components. This spot shielding has the advantage of being lighter than more traditional technics. These preamplifiers have low-noise input stages. Their dynamic range is about $100 \mathrm{~dB}$, which allows weak signals to be measured in the presence of the large voltage signals induced by the rotation of the spacecraft in the DC magnetic field.They benefit from a specific power supply which is also realized in MCM-V technology and corresponds to a fourth cube. A specific SCM calibration signal is generated inside the Preamplifier box. The use of this calibration is discussed in the next section. The mass and power consumption of SCM preamplifier are $200 \mathrm{~g}$ and $75 \mathrm{~mW}$, respectively, which is compliant with specifications.

\section{Calibrations and tests}

The experiment transfer function and NEMI are given in Figure 7 and 8; they were measured on the ground in a quiet site, at Chambon la Forêt, France. Figures 9 and 10 show pictures 


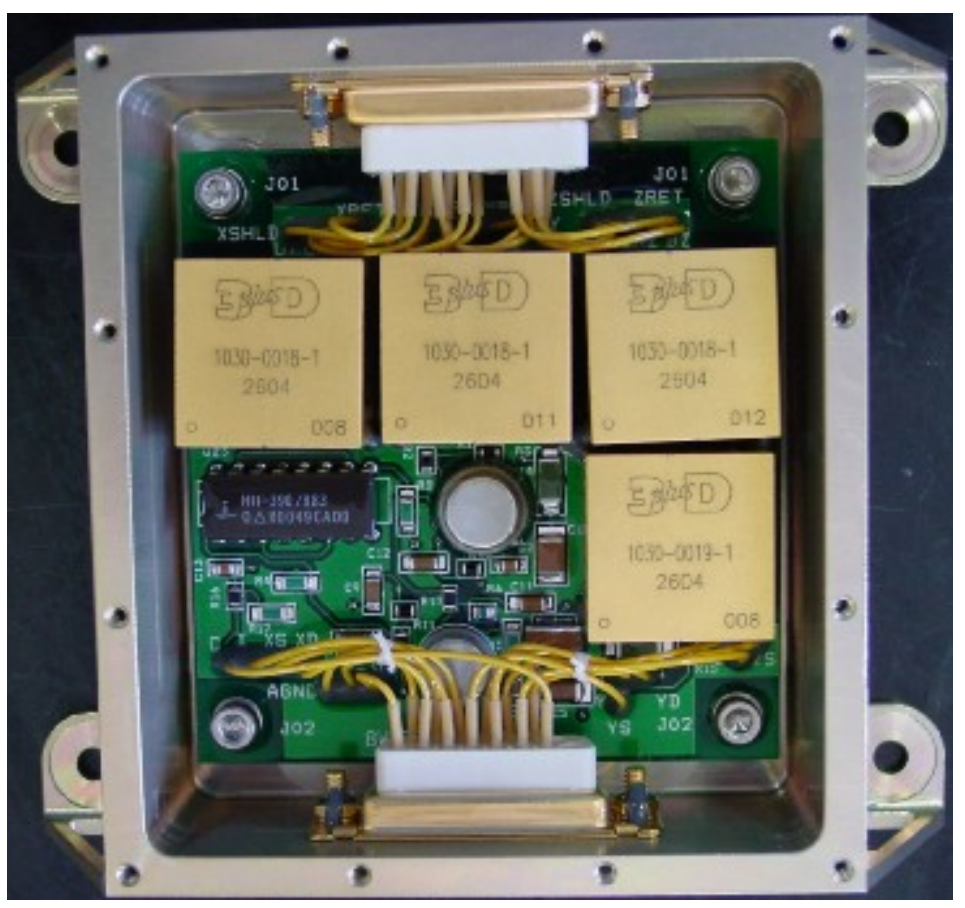

Fig. 6 Preamplifier box. The 3 upper cubes correspond to the 3 antennas preamplifiers, the fourth one is for power regulation. They are manufactured in 3D technology . The electronics for the in-flight calibration is also shown on the PCB. The preamplifier box size is $95 \mathrm{~mm}$ x $81 \mathrm{~mm}$ (109 with the mounting 'ears ') x 30 $\mathrm{mm}$

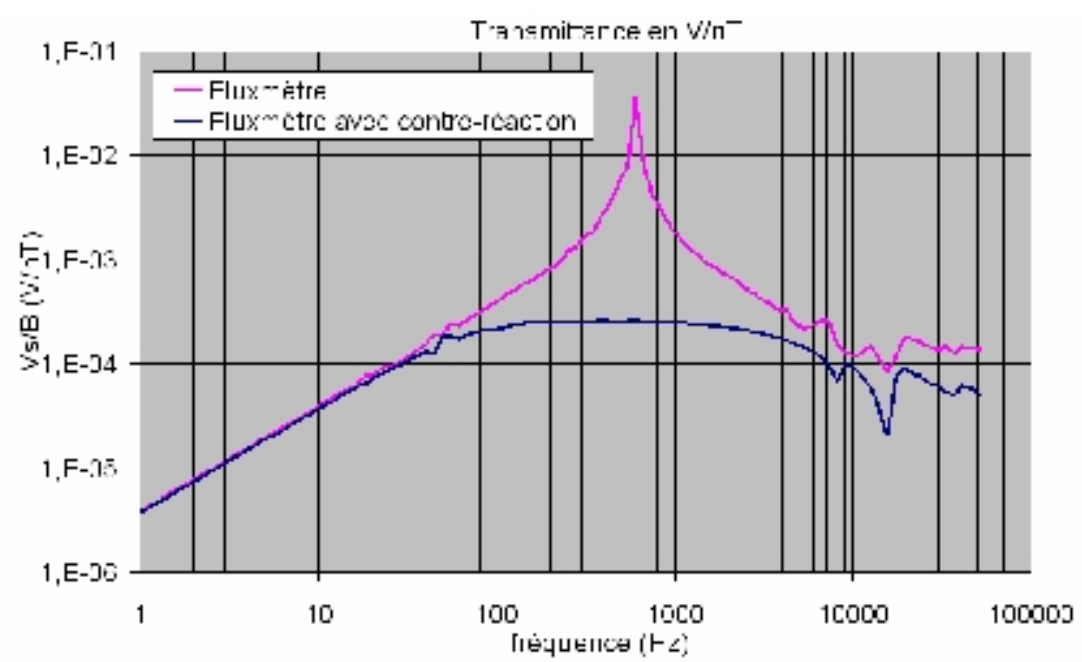

Fig. 7 Frequency response (transfer function) of the SCM with feedback (blue) and without (pink) 
Table 1 NEMI of FM1

\begin{tabular}{llll}
\hline FM1 & $10 \mathrm{~Hz}$ & $100 \mathrm{~Hz}$ & $1 \mathrm{kHz}$ \\
\hline $\mathrm{X}$ & 0.69 & 0.070 & 0.022 \\
$\mathrm{Y}$ & 0.65 & 0.072 & 0.021 \\
$\mathrm{Z}$ & 0.64 & 0.077 & 0.021 \\
\hline
\end{tabular}

Table 2 NEMI of FM2

\begin{tabular}{llll}
\hline FM2 & $10 \mathrm{~Hz}$ & $100 \mathrm{~Hz}$ & $1 \mathrm{kHz}$ \\
\hline $\mathrm{X}$ & 0.64 & 0.0699 & 0.020 \\
$\mathrm{Y}$ & 0.65 & 0.0698 & 0.020 \\
$\mathrm{Z}$ & 0.645 & 0.076 & 0.022 \\
\hline
\end{tabular}

Table 3 NEMI of FM3

\begin{tabular}{llll}
\hline FM3 & $10 \mathrm{~Hz}$ & $100 \mathrm{~Hz}$ & $1 \mathrm{kHz}$ \\
\hline $\mathrm{X}$ & 0.61 & 0.070 & 0.0196 \\
$\mathrm{Y}$ & 0.66 & 0.067 & 0.016 \\
$\mathrm{Z}$ & 0.74 & 0.066 & 0.019 \\
\hline
\end{tabular}

Table 4 NEMI of FM4

\begin{tabular}{llll}
\hline FM4 & $10 \mathrm{~Hz}$ & $100 \mathrm{~Hz}$ & $1 \mathrm{kHz}$ \\
\hline $\mathrm{X}$ & 0.71 & 0.079 & 0.017 \\
$\mathrm{Y}$ & 0.76 & 0.08 & 0.019 \\
$\mathrm{Z}$ & 0.74 & 0.077 & 0.019 \\
\hline
\end{tabular}

of the experiment during these measurements. The NEMI of each flight model are shown in tables 1 to 5. The largest NEMI is $0.76 \mathrm{pT} / \sqrt{\mathrm{Hz}}$ at $10 \mathrm{~Hz}$ which complies with the specified value $(1 \mathrm{pT} / \sqrt{\mathrm{Hz}})$. At $100 \mathrm{~Hz}$ the largest NEMI is $0.08 \mathrm{pT} / \sqrt{\mathrm{Hz}}$, and at $1 \mathrm{kHz}$ it is 0.022 $\mathrm{pT} / \sqrt{H z}$.

It can be seen that they are quite close. The transfer functions are also almost identical, less than $1 \mathrm{~dB}$ differences between the models. In order to determine the polarisation of the waves on each satellite and to compare accurately data from the five satellites, careful measurements of the angle between each magnetic axis and its corresponding mechanical axis have been made. These angles may be a few degrees, but they need to be known with precision. The estimated error in the knowledge of the magnetic axis is 0.5 degree which is less than the 1 degree in specifications. For example the angle of $\mathrm{X}$ sensor of the flight model number 3 (FM3) is 0.2 degree. For each sensor the angle difference between mechanical axis and magnetic axis can be neglected. Thus the magnetic field can be accurately

Table 5 NEMI of FM5

\begin{tabular}{llll}
\hline FM5 & $10 \mathrm{~Hz}$ & $100 \mathrm{~Hz}$ & $1 \mathrm{kHz}$ \\
\hline $\mathrm{X}$ & 0.66 & 0.065 & 0.016 \\
$\mathrm{Y}$ & 0.70 & 0.074 & 0.016 \\
$\mathrm{Z}$ & 0.72 & 0.069 & 0.016
\end{tabular}




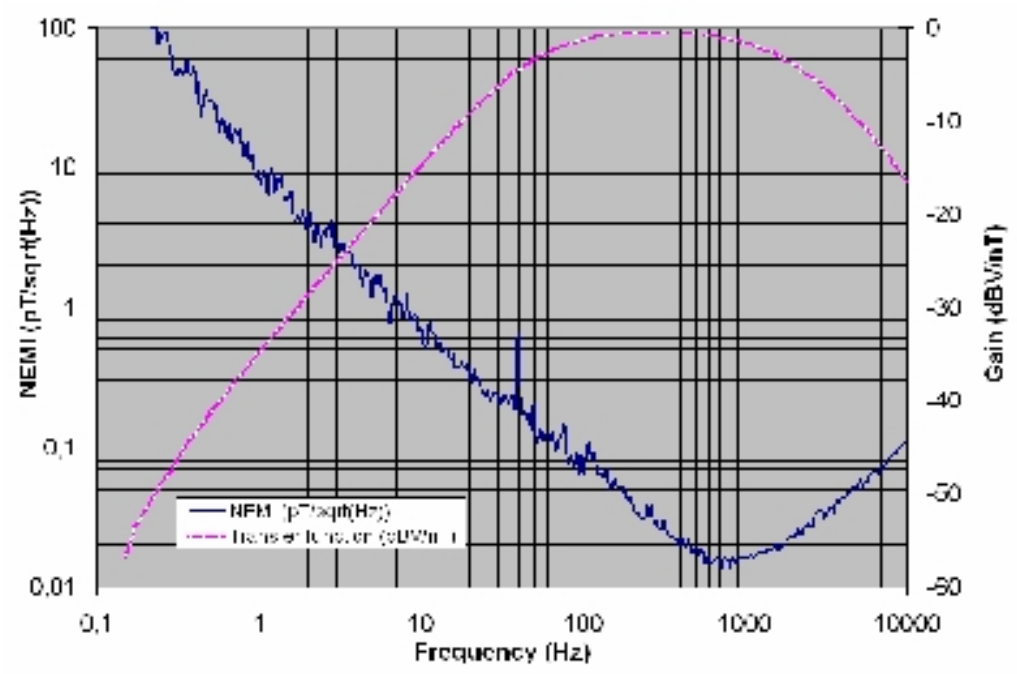

Fig. 8 Transfer function (pink) in dBV/nT and NEMI (in blue) in pT/ $\sqrt{\mathrm{Hz}}$ of THEMIS search coil measured in the calibration facility at Chambon la Forêt

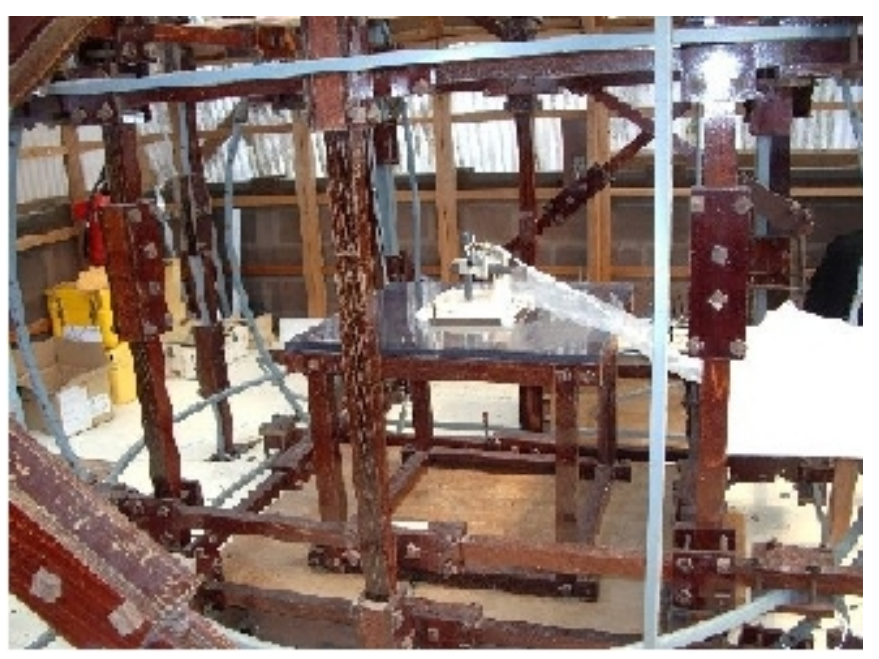

Fig. 9 SCM placed at the center of three Helmholtz coils that generate the test magnetic field. A set of other coils cancel the effect of the earth's magnetic field

transformed into any required reference frame. A free running onboard oscillator generates a $9 \mathrm{~Hz}$ triangular wave used to check the transfer function inflight. A digital command is activated by the DFB to connect this signal to the feedback winding of the sensors. This signal is detected by the primary winding, and seen in Bx, By, and Bz data. The default duration is 30 seconds with a maximum of 60 seconds. This signal shape is shown in figure 11 and gives rich harmonic contents useful for calibration throughout most of the bandwidth. Further signal processing takes place inside the IDPU, on a single board, together with the EFI instrument. The analog signals output by SCM are filtered, sampled, and converted to 


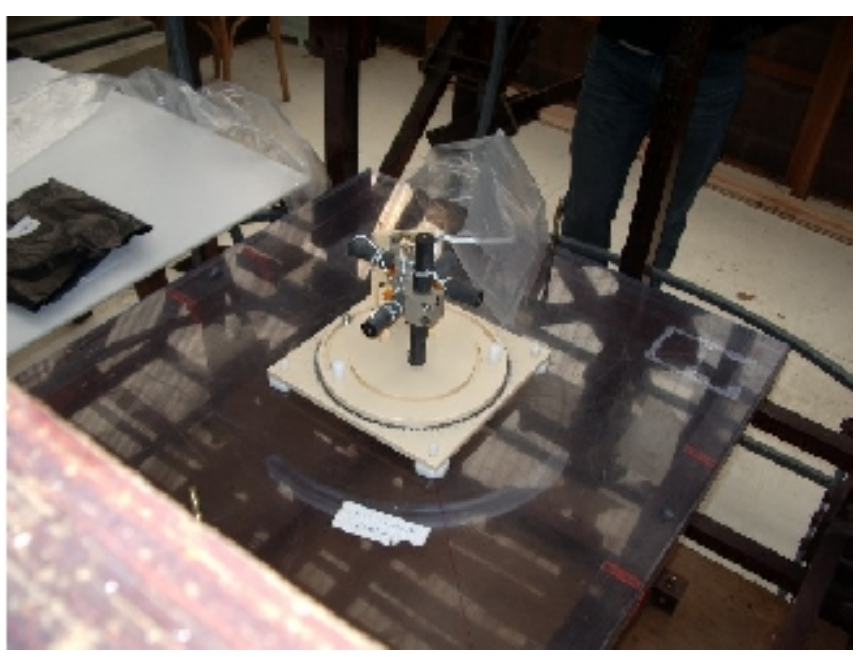

Fig. 10 Tri-axis SCM on a turn-table during tests to determine magnetic axis

Table 6 Telemetry modes for SCM

\begin{tabular}{|c|c|c|}
\hline APID & Processing & Characteristics and comments \\
\hline 440 & Filter bank (fbk) & $\begin{array}{l}\text { Mean value of the signal in } 6 \text { frequency bands } \\
\text { kHz: [4-2]; [1-0.5]; Hz: [256-128]; [64-32]; [16-8]; [4-2] } \\
\text { Sampling rate: } 1 / 16 \text { to } 8 \text { S/s } \\
\text { There are only } 2 \text { inputs to be shared within } 3 \mathrm{SCM} \text { and } 12 \mathrm{EFI} \\
\text { components }\end{array}$ \\
\hline 444 & Fast survey (scf) & $\begin{array}{l}\text { Waveform data for the } 3 \mathrm{SCM} \text { components } \\
\text { Sampling rate within } 2 \text { to } 256 \mathrm{~S} / \mathrm{s} \text {, nominal value is } 8\end{array}$ \\
\hline $\begin{array}{l}448 \\
44 C\end{array}$ & Particle burst (scp) & as 444 but nominal value is $128 \mathrm{~S} / \mathrm{s}$ \\
\hline $\begin{array}{l}44 \mathrm{C} \\
44 \mathrm{D}\end{array}$ & $\begin{array}{l}\text { Wave burst (scw) } \\
\text { Particle burst spectra (ffp) }\end{array}$ & $\begin{array}{l}\text { as } 444 \text { but nominal value is } 8192 \mathrm{~S} / \mathrm{s} \\
\text { Compressed FFT with } 16,32 \text { or } 64 \text { frequency lines, nominal } \\
\text { value is } 32\end{array}$ \\
\hline & & $\begin{array}{l}\text { Sampling rate from } 1 / 4 \text { to } 8 \text { Spectra/s, nominal value is } 1 \\
\text { There are only } 4 \text { inputs to be shared within } 20 \text { possible signals } \\
\text { including the } 3 \text { SCM components }\end{array}$ \\
\hline $44 \mathrm{E}$ & Wave burst spectra (ffw) & $\begin{array}{l}\text { as } 44 \mathrm{D} \text { but nominal values are } 64 \text { frequency lines and } 8 \text { Spec- } \\
\text { tra/s }\end{array}$ \\
\hline
\end{tabular}

digital in the IDPU. Taking into account that SCM measurements is digitized with 16 bits and that it must comply with the NEMI requirements, the SCM measurement is likely to saturate for an AC magnetic field about $1000 \mathrm{nT}$. DC magnetic field being detected by SCM at the spin frequency, SCM is saturated around $4 \mathrm{R}_{E}$. The different modes of data transmission are described in the IDPU/DFB paper. SCM data is transmitted in the following modes: Fast Survey (Application ID 444) at sampling rates between $2 \mathrm{~Hz}$ and $256 \mathrm{~Hz}$, Particle Burst (App. ID 448) at 2-256 Hz, Wave Burst (App. ID 44C) at $512 \mathrm{~Hz}$ to $8 \mathrm{kHz}$, Spectra (App. ID 44D and 4E), and Filter Banks (App. ID 440) where the power in six frequency bands is calculated: 4-2 kHz, 1-0.5 kHz, 256-128 Hz, 64-32 Hz, 16-8 Hz, and 4-2 Hz (see table 6 for more details). 


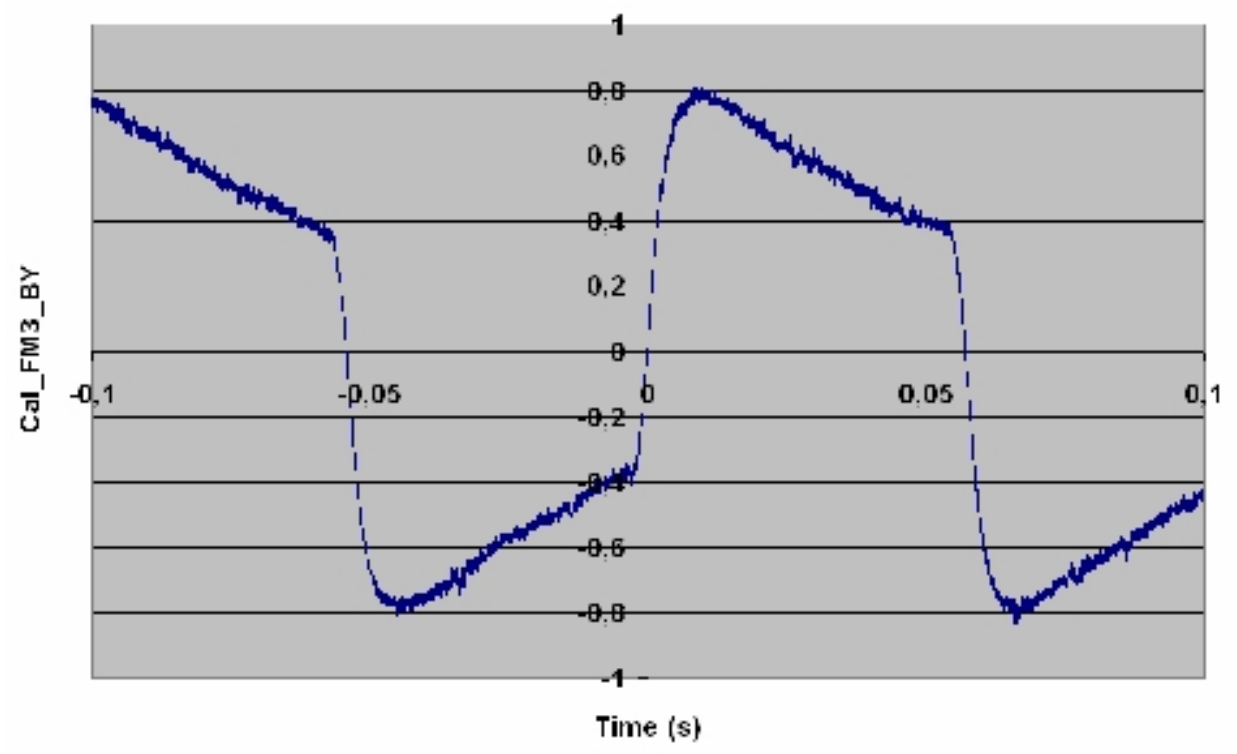

Fig. 11 Output of the calibration signal when cal is ON

\section{Summary and conclusions}

The SCM instruments implemented on the five THEMIS probes measure the 3D magnetic field fluctuations in the frequency bandwidth from $0.1 \mathrm{~Hz}$ to $4 \mathrm{kHz}$. The weight and power consumption comply with THEMIS requirements. They extend with appropriate NEMI and sufficient overlap, the measurements of the FGM beyond the $1 \mathrm{~Hz}$ range. We have described the design of THEMIS SCM. Tests and calibrations carried out in a quiet site, at Chambon la Forêt, demonstrate that the five sets of triaxial search coils cover the same frequency range, have the same frequency response, and the same NEMI. SCM instruments fulfill all mission requirements. The NEMI at $10 \mathrm{~Hz}$ is smaller than $0.76 \mathrm{pT} / \sqrt{\mathrm{Hz}}$ for each instrument while the NEMI at $1 \mathrm{kHz}$ is about $20 \mathrm{fT} / \sqrt{\mathrm{Hz}}$. Onboard calibration is usually performed once per orbit in order to check the stability of the transfer function. The magnetic axis are known to better than 1 degree; as requested. The $0.1 \mathrm{~Hz}$ to $4 \mathrm{kHz}$ frequency range is covered by EFI and SCM, in the same manner. SCM and EFI data data are filtered, processed and transmitted to the ground via THEMIS DFB/IDPU. The 5x3 SCMs work nominally.

\section{References}

1. Bozorth, R.M., Chapin, D.M.: Demagnetizing factors of rods. J. Appl. Phys. 13, 320-326 (1942)

2. Bulanov, S.V., Pegoraro, F., Sakharov, A.S.: Magnetic reconnection in electron dynamics. Phys. Fluids B 4, 2499-2508 (1992)

3. Cornilleau-Wehrlin, N., Chauveau, P., Louis, S., Meyer, A., Nappa, J., Perraut, S., Rezeau, L., Robert, P., Roux, A., de Villedary, C., de Conchy, Y., Friel, L., Harvey, C.C., Hubert, D., Lacombe, C., Manning, R., Wouters, F., Lefeuvre, F., Parrot, M., Pinçon, J.L., Poirier, B., Kofman, W., Louarn, P.: The Cluster Spatio-temporal Analysis of Field Fluctuations (STAFF) experiment. Space Science Reviews 79, 107136 (1997)

4. Cornilleau-Wehrlin, N. and G. Chanteur and S. Perraut and L. Rezeau and P. Robert and A. Roux and C. de Villedary and P. Canu and and M. Maksimovic and Y. de Conchy and D. Hubert and C. Lacombe and 
F. Lefeuvre and M. Parrot and J.-L Pinçon and P. M. E. Décréau and C. C. Harvey and P. Louarn and O. Santolik and H. St. Alleyne and M. Roth and T. Chust and O. Le Contel and STAFF team: First results obtained by the Cluster STAFF experiment. Annales Geophysicae 21, 437-456 (2003)

5. Le Contel, O., Roux, A., Robert, P., Coillot, C., Bouabdellah, A., la Porte, B., Alison, D., Ruocco, S., Bromund, K., Chaston, C.C., Angelopoulos, V., Cully, C.: First results of THEMIS Search Coil Magnetometers (scm). Space Sci. Rev. this issue (2007)

6. Lui, A.T., Lopez, R.E., Anderson, B.J., Takahashi, K., Zanetti, L.J., McEntire, R.W., Potemra, T.A., Klumpar, D.M., Greene, E.M., Strangeway, R.: Current disruption in the near-Earth neutral sheet region. J. Geophys. Res. 97, 1461 (1992)

7. Lui, A.T.Y.: Current controversies in magnetospheric physics. Rev. Geophys. 39(4), 535-563 (2001)

8. Mandt, M.E., Denton, R.E., Drake, J.F.: Transition to whistler mediated magnetic reconnection. Geophys. Res. Lett. 21(1), 73-77 (1994)

9. Osborn, J.A.: Demagnetizing factors of the general ellipsoid. Phys. Rev. 67(11-12), 351-357 (1945)

10. Ripka, P.: Magnetic sensors and magnetometers. Artech house (2001)

11. Roux, A., Perraut, S., Robert, P., Morane, A., Pedersen, A., Korth, A., Kremser, G., Aparicio, B., Rodgers, D., Pellinen, R.: Plasma sheet instability related to the westward traveling surge. J. Geophys. Res. 96, 17,697 (1991) 